\title{
Bilateral Optic Disc Anomalies Associated with PAX2 Mutation in a Case of Potter Sequence
}

\author{
Mizuki Tagami ${ }^{a}$ Shigeru Honda ${ }^{a}$ Ichiro Moriokab \\ Masafumi Matsuo ${ }^{\mathrm{b}} \quad$ Akira Negi $^{\mathrm{a}}$ \\ aDepartment of Surgery, Division of Ophthalmology, and bepartment of \\ Pediatrics, Kobe University Graduate School of Medicine, Kobe, Japan
}

\section{Key Words}

Potter sequence $\cdot$ Optic nerve hypoplasia $\cdot$ Papillorenal syndrome $\cdot$ PAX2 mutation

\begin{abstract}
Purpose: To describe the ophthalmic findings in the fundus of a Japanese infant with Potter sequence having a mutation in the PAX2 gene.
\end{abstract}

Methods: A 1-month-old infant diagnosed with Potter sequence who had bilateral renal hypoplasia and a mutation in the PAX2 gene was subjected to detailed ophthalmic examination.

Results: Funduscopy revealed a megalopapilla with marked excavation in the right eye. The left optic disc showed a similar abnormality, but to a lesser extent. B-mode ultrasonography and magnetic resonance imaging detected giant cystic lesions occupying the optic nerve head in both eyes. According to these results, we diagnosed this patient as having papillorenal syndrome (PRS) associated with a PAX2 mutation. Conclusions: This report shows ophthalmic findings in the youngest patient with PRS and PAX2-associated Potter sequence. Optic disc anomalies may be involved in some infants with Potter sequence. We anticipate an increase in opportunities for ophthalmic examinations in infants with diseases such as Potter sequence with previously high mortality rates.

\section{Introduction}

Potter syndrome results from oligohydramnios secondary to renal agenesis, which was first reported by Potter [1]. The ophthalmic features of a child with Potter syndrome have not been clarified since current knowledge of the disease is lacking due to a high neonatal mortality rate.

Recently, survival rates of infants with renal dysfunction diseases (i.e. polycystic kidneys, renal hypoplasia, dysplastic kidneys and posterior urethral valve anomalies) have 
increased with improved intensive pediatric care [2]. The abovementioned diseases show similar although slightly milder symptoms compared with Potter syndrome. These entities are usually called Potter sequence [3]. Although Potter sequence is not well documented in ophthalmology, abnormal ocular findings associated with renal hypoplasia were first described by Rieger in 1977 as papillorenal syndrome (PRS), also known as renal coloboma syndrome [4]. PRS is considered to be an extremely rare autosomal disease consisting of bilateral optic disc anomalies associated with hypoplastic kidneys, implicating $P A X 2$ and $P A X 6$ as the causative genes [5-7].

The fundus characteristics of PRS consist of the presence of numerous cilioretinal vessels with absent or rudimentary central retinal vessels. A supranasal visual field defect corresponding to retinal hypoplasia and an abnormal retinal and choroidal perfusion at the inferotemporal area can be observed. In many cases, examination of the kidney or urinary tract is lacking. Hence, the ocular findings are frequently misdiagnosed as glaucoma (in particular normal tension glaucoma), colobomas, or atypical morning glory anomalies [7].

In the Western world, several cases of PRS with varying degrees of severity have been diagnosed mainly in school age children or young adults. However, there are no reports describing ophthalmic findings of PRS in early infancy. Furthermore, no report regarding ophthalmic findings in Potter sequence exists.

Here, we report a case of Potter sequence with a mutation in the PAX2 gene which exhibited similar abnormal optic nerve heads as seen in PRS of children and adults.

\section{Case Report}

A male Japanese newborn with a birth weight of 2,410 g was delivered by caesarean section at the 37 th week of gestation due to oligohydramnios. The infant was immediately admitted to the neonatal intensive care unit and was diagnosed with Potter sequence because of bilateral renal hypoplasia with pulmonary hypoplasia. He survived due to cardiopulmonary intensive care including peritoneal dialysis. A genetic analysis of the PAX2 gene found a heterozygous insertion of a $\mathrm{G}$ at position 619 [8].

He was referred to ophthalmology for suspected exotropia at the age of 45 days. At the initial consultation, mild exotropia was confirmed. Slit-lamp examination revealed no abnormality in the cornea, iris and anterior chamber of both eyes. The macula and peripheral retina appeared normal in the funduscopic examination. However, optic disc abnormalities were observed bilaterally. The right fundus showed a megalopapilla with marked excavation and absent central vessels. All vessels had entry or exit points at the disc margin ( $\underline{\text { fig. 1 }}$ a). These findings resemble those found in papillary coloboma or morning glory syndrome. B-mode ultrasonography and orbital magnetic resonance imaging (MRI) detected a giant cystic lesion at the right optic nerve head (fig. 1c, d). The left optic disc showed a similar abnormality, but to a lesser extent (fig. 1b, d). We diagnosed PRS with the phenotype of Potter sequence and abnormal development of the optic nerve associated with a mutation in exon 2 of PAX2.

\section{Discussion}

In this report, we describe the ophthalmic findings in a case of Potter sequence with a mutation in the $P A X 2$ gene. The case had optic disc hypoplasia observed by funduscopic examination. B-mode ultrasonography and MRI revealed that the optic nerve heads were replaced by giant cystic lesions. 
A few studies have reported PRS with PAX2 and PAX6 mutations [5-7]. Yoshimura et al. [9] initially reported that a heterozygous insertion of guanine at position 619 in the $P A X 2$ gene caused a frameshift, which resulted in a truncated protein due to a termination codon at the 26th amino acid. They hypothesized that abnormal development of the optic stalk leads to the abnormal optic nerve head seen in congenital optic nerve anomalies with $P A X 2$ mutations. Interestingly, the mutation found in the present case was exactly the same as in their report. They further proposed the diagnostic value of the presence of a mutational hot spot in the PAX2 gene $[9,10]$.

On the other hand, Parsa et al. [7] hypothesized that a primary deficiency in vascular development compromises growth of substantial portions of the retina and choroid and accounts for the types of ocular abnormalities seen in their subjects. In this report, $\mathrm{B}$-mode ultrasound examination and MRI revealed giant cystic lesions in the place of the optic discs. The right optic disc showed marked excavation with absent central vessels. All retinal vessels had their entry and exit points at the disc margin. We speculate that both the abnormal development of the optic stalk and a primary deficiency in vascular development contributed to the abnormal optic nerve development and compromised growth of substantial portions of the retina and choroids, which was associated with a $P A X 2$ mutation. Since the present case showed that Potter sequence shares many ophthalmic features with PRS including PAX2 mutation, some cases with Potter sequence might be involved in PRS, although they could not be referred to an ophthalmologist due to lethal events. However, more cases are necessary to draw more definitive conclusions.

Due to recent progress in the quality of intensive pediatric care, more opportunities to examine Potter sequence cases may arise. Hence, ophthalmic findings of Potter sequence in the early postnatal period, coupled with the possibility of long-term observation due to increased survival rates, will lead to a better understanding of the clinical course, treatment, and outcome of this disease. 


\begin{tabular}{|c|c|c|c|}
\hline $\begin{array}{l}\text { Case Reports in } \\
\text { Oplitallaloy }\end{array}$ & $\begin{array}{l}\text { Case Rep Ophthalmol 2010;1:94-98 } \\
\text { DOI: 10.1159/000321625 }\end{array}$ & $\begin{array}{l}\text { Published online: } \\
\text { November 29, } 2010\end{array}$ & $\begin{array}{l}\text { () } 2010 \text { S. Karger AG, Basel } \\
\text { ISSN } 1663-2699 \\
\text { www.karger.com/cop }\end{array}$ \\
\hline
\end{tabular}

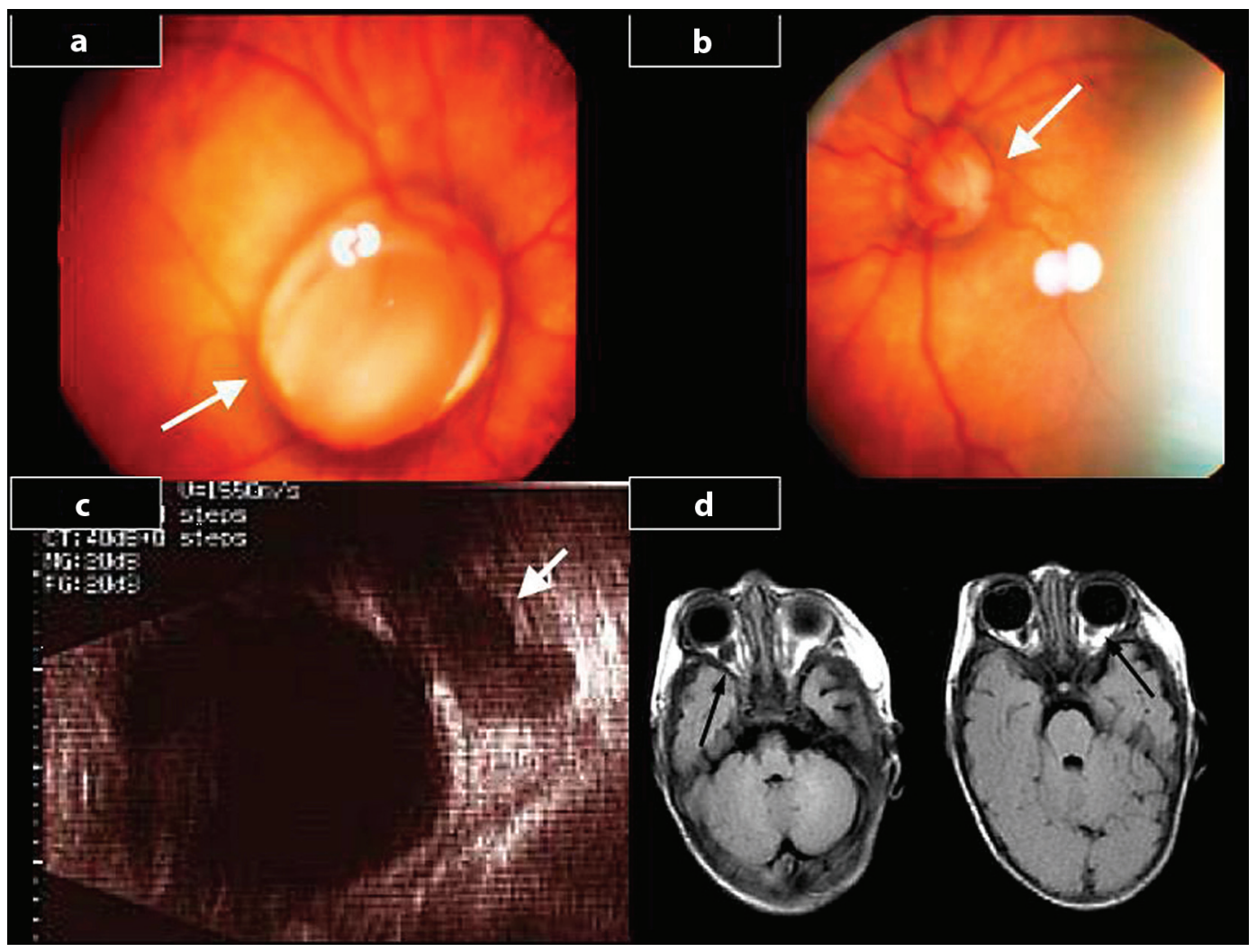

Fig. 1. Fundus photographs (30 degree) showing bilateral optic disc abnormalities. The right fundus showed a megalopapilla with marked excavation of the optic disc, absence of central vessels, with vessels having their entry or exit points at the disc margins (thick arrows) (a). The left fundus had milder findings (b). B-mode ultrasound examination and MRI showing a giant cystic lesion in the optic disc head (thin arrow and black arrows) $(\mathbf{c}, \mathbf{d})$. 


\section{References}

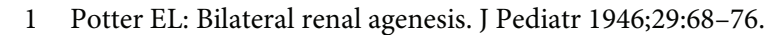

2 Klaassen I, Neuhaus TJ, Mueller-Wiefel DE, Kemper MJ: Antenatal oligohydramnios of renal origin: long-term outcome. Nephrol Dial Transplant 2007;22:432-439.

3 Curry CJ, Jensen K, Holland J, Miller L, Hall BD: The Potter sequence: a clinical analysis of 80 cases. Am J Med Genet 1984;19:679-702.

4 Rieger G: Zum Krankheitsbild der Handmannschen Sehnerven-Anomalie: 'Windenbluten'-('Morning Glory')Syndrom? Klin Monbl Augenheilkd 1977;170:697-706.

5 Sanyanusin P, Schimmenti LA, McNoe LA, et al: Mutation of the PAX2 gene in a family with optic nerve colobomas, renal anomalies and vesicoureteral reflux. Nat Genet 1995;9:358-364.

6 Azuma N, Yamaguchi Y, Hanada H, Tadahiro K, Asuka A, Kawase E, Yamada M: Mutation of the PAX6 gene detected in patients with a variety of optic-nerve malformations. Am J Hum Genet 2003;72:1565-1570.

7 Parsa CF, Silva ED, Sundin OH, Goldberg MF, De Jong MR, Sunness JS, Zeimer R, Hunter DG: Redefining papillorenal syndrome: an underdiagnosed cause of ocular and renal morbidity. Ophthalmology 2001;108:738749.

8 Fujioka K, Morioka I, Nozu K, Nishimoto M, Amano M, Tagami M, Honda S, Yokoyama N, Yamada H, Iijima K, Matsuo M: A surviving case of papillorenal syndrome with the phenotype of Potter sequence. Pediatr Int, in press 2010.

$\checkmark 9$ Yoshimura K, Yoshida S, Yamaji Y, Komori A, Yoshida A, Hatae K, Kubota T, Ishibashi T: De novo insG619 mutation in PAX2 gene in a Japanese patient with papillorenal syndrome. Am J Ophtalmol 2005;139:733-735.

10 The Human PAX2 Allelic Variant Database. Available at http://pax2.hgu.mrc.ac.uk. Accessed July 28, 2008. 